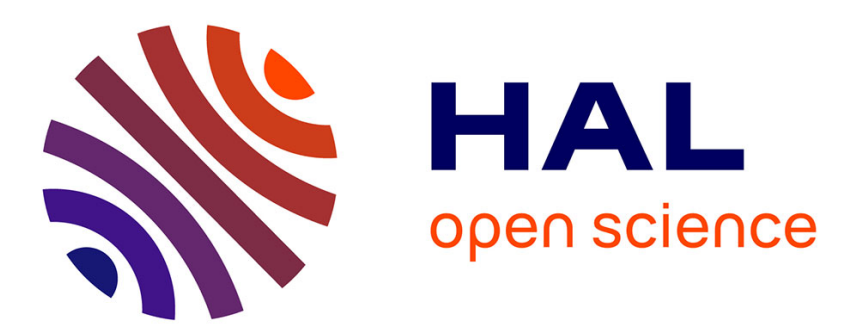

\title{
Estimation of cost functions in a data poor environment: the case of capacity estimation in fisheries \\ Sean Pascoe
}

\section{To cite this version:}

Sean Pascoe. Estimation of cost functions in a data poor environment: the case of capacity estimation in fisheries. Applied Economics, 2008, 39 (20), pp.2643-2654. 10.1080/00036840600722257 . hal00581974

\section{HAL Id: hal-00581974 \\ https://hal.science/hal-00581974}

Submitted on 1 Apr 2011

HAL is a multi-disciplinary open access archive for the deposit and dissemination of scientific research documents, whether they are published or not. The documents may come from teaching and research institutions in France or abroad, or from public or private research centers.
L'archive ouverte pluridisciplinaire HAL, est destinée au dépôt et à la diffusion de documents scientifiques de niveau recherche, publiés ou non, émanant des établissements d'enseignement et de recherche français ou étrangers, des laboratoires publics ou privés. 


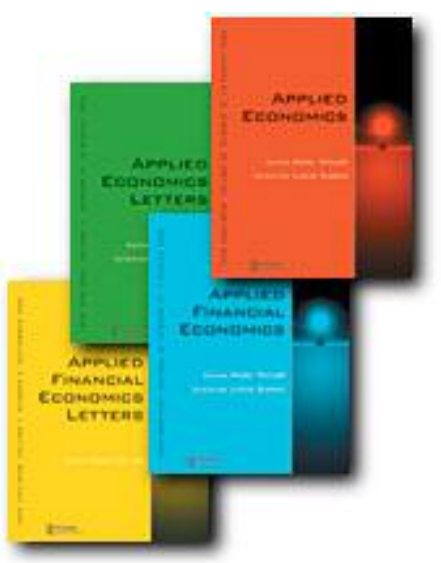

Estimation of cost functions in a data poor environment: the case of capacity estimation in fisheries

\begin{tabular}{|r|l|}
\hline Journal: & Applied Economics \\
\hline Manuscript ID: & APE-05-0435.R1 \\
\hline Journal Selection: & Applied Economics \\
\hline JEL Code: & $\begin{array}{l}\text { C61 - Optimization Techniques|Programming Models|Dynamic } \\
\text { Analysis <, C81 - Methodology for Collecting, Estimating, and } \\
\text { Organizing Microeconomic Data <, C21 - Cross-Sectional } \\
\text { Models|Spatial Models <, D24 - Production|Capital and Total Factor } \\
\text { Productivity|Capacity <, Q22 - Fishery < }\end{array}$ \\
\hline Keywords: & $\begin{array}{l}\text { translog cost function, Data Envelopment Analysis, capacity, } \\
\text { fisheries }\end{array}$ \\
\hline
\end{tabular}

powered by ScholarOne

Manuscript Central ${ }^{\text {TH }}$ 


\title{
Estimation of cost functions in a data poor
}

\section{environment: the case of capacity estimation in}

\section{fisheries}

Running title: Estimating capacity from cost functions with poor data

\begin{abstract}
Fisheries economic analysis is often handicapped by the lack of adequate data to undertake robust econometric analyses. In this study, a translog cost function was required to estimate the potential direction of adjustment in a UK fleet segment if a new regulatory regime was introduced. However, the available data were not appropriate for such estimation. Data Envelopment Analysis (DEA) was used to modify the data subsequently used in the estimation of the long run cost function. The resulting model appears robust and is consistent with economic theory and the supporting evidence produced using DEA.
\end{abstract}

Key words: translog cost function, Data Envelopment Analysis, capacity, fisheries 


\section{Introduction}

Applied economic analysis in fisheries is characterised by limited, and often poor quality, data. This is especially so for fisheries economic data. While price information is often readily available, largely due to the predominance of fish auction markets as a means of distributing the catch, information on the costs of fishing is extremely limited. Collection of this information is costly, as it is usually undertaken through personal interviews. Further, the number of participants in a given fishery ${ }^{1}$ is also relatively small, resulting in small sample sizes for particular fleet segments operating in particular areas. Further, the industry is often subject to many other systems of data collection, primarily for scientific purposes and involving activity information (catch, fishing effort, vessel characteristics etc). These data are usually collected through some mandatory requirement, so fishers are reluctant to participate in "voluntary" surveys to provide detailed information on their individual financial situation. As a result, economic panel data series are often short and unbalanced, often consisting of a one period cross section rather than a true panel data set.

Despite this lack of reliable economic data, policy analysis is still required. This requires the creative use of the available information in order to derive robust policy conclusions.

The study that is the focus of this paper is one such example where combining techniques enables the estimation of reliable econometric results that can be used to inform policy advice. The particular issue in this case was the potential size and 
structure of a set of UK fishing vessels if a new regulatory process was introduced that would facilitate restructuring of the industry. This required the identification of the extent of excess capacity in the existing fleet, and the fully utilised level of capacity of the vessels that were most likely to remain following adjustment. The use of cost functions was considered the most appropriate approach given the expectation that fleet adjustment would move in the direction of the least cost producers. ${ }^{2}$ This essentially requires the estimation of a long run cost function, as the assumption is both capital and its utilisation can be changed. However, the available data for the estimation of the cost function were primarily short run in nature, and deficient in terms of variable input use.

To overcome the data deficiencies, estimates of capacity utilisation and inefficiency were derived using data envelopment analysis, and the cost information "adjusted" to represent fully utilised capital. Given these "adjusted" data, cost functions were estimated and used to determine the optimal scale and potential rents for the UK demersal trawl fleets, and the reduction in fleet size that may be necessary to achieve these rents.

\section{Policy context}

Despite over 20 years of structural adjustment through the multiannual guidance programme (MAGP), part of the structural policy of the Common Fisheries Policy (CFP), overcapacity remains a significant issue for European fisheries. DG Fish (2000) estimated that, in 2000 , there was more than 40 per cent overcapacity in the EU fleet as a whole. This has been further exacerbated by the subsequent 
substantial decline in many key whitefish stocks in EU fisheries. Reductions in total allowable catches (TACs) in excess of 50 per cent were imposed for many North Sea whitefish stocks in 2002, with stocks in other areas subject to TAC reductions of between 10 and 30 per cent (DG Fish 2001). Further cuts in quotas of the order of between 30 and 40 per cent were made in 2003, and these lower quotas were carried through to 2004 also.

Of particular concern to the UK industry is the state of the cod stocks. These are still considered to be outside safe scientific limits in the North Sea, English Channel and Irish Sea, with scientific advice being to close the cod fishery in the North Sea and Irish Sea and reduce fishing mortality by 90 per cent in the English Channel (ICES 2003). While such extreme measures have not been implemented, the low cod stock creates particular problems for the UK demersal trawl fleets operating in these areas. Cod is the major target species for these vessels, and the UK takes the largest share of total catch of cod. Restrictions on days fished and reduced quota results in many fishers operating at less than full capacity with resultant economic inefficiency. In 2001, 35 per cent of whitefish vessels were making a financial loss or no profit, and average financial profit (i.e. before depreciation costs were considered) was only 2 per cent of earnings (Rural Development Committee 2003). The most recent reductions in catch quotas are likely to result in a significant proportion of the fleet being economically unsustainable. 
The Prime Minister's Strategy Unit (2004) recommended urgent actions to reduce capacity in the whitefish sector through an additional decommissioning scheme to permanently remove fishing capacity and a series of short-term tie-ups to relieve pressure on the stocks. In addition, the Unit proposed that individual tradeable rights for resource access in the form of individual transferable quotas (ITQs) be introduced into all fleet segments by the end of 2006 .

The latter proposal is aimed at providing incentives for continuing fleet rationalisation and enhancing long term economic performance. ITQs have been successful in many fisheries internationally in facilitating fleet adjustment and removing excess capacity. The theory and practice underlying the use of ITQs is well documented in the fisheries economics literature (e.g. Hannesson, 1991). Excess capacity is removed through quota trade, with some vessels exiting the fishery and the remaining vessels consolidating the available quota. Incentives are created to reduce the costs of capture, with fleet adjustment favouring the least cost producers and reinvestment occurring in vessels that will operate at minimum average cost.

\subsection{The UK demersal trawl fleet}

The UK demersal trawl fleet undertakes three main activities - otter trawling, danish seining and Nephrops trawl. Otter trawlers and danish seiners both target similar whitefish species, but using different types of trawl gear, while Nephrops trawlers target primarily Nephrops (also known as scampi, langoustine and Dublin Bay prawns). In 2002, there were 929 demersal trawlers over 10 metres in length ${ }^{3}$ 
(DEFRA 2003), of which around 230 were Nephrops trawlers. Between 1999 and 2002, the over $10 \mathrm{~m}$ demersal trawl fleet decreased by almost 25 per cent as a result of decommissioning programmes and voluntary retirement as a result of the adverse economic conditions facing the industry.

The demersal trawl fleet is currently regulated through a series of input and output controls. Licence limitations restrict entry to the fishery, while a unitisation system restrictions boat replacement. Aggregate total allowable catches are set at the European level for each stock of the key species and distributed to the individual Member States in relatively fixed proportion. In the UK, these are further distributed to individual vessels greater than $10 \mathrm{~m}$ in length in the form of fixed quota allocations. Although termed "fixed", the quotas are transferable on an annual basis through quota leasing. Permanent quota transfers can also be arranged, although the restrictions associated with this have prevented wide-scale permanent transfer of quota.

The whitefish trawlers (otter trawlers and seiners) operate primarily in the North Sea, English Channel, Celtic Sea and Irish Sea targeting cod and other whitefish species. The catch composition varies in the different areas, with the English Channel trawlers being characterised by a relatively high proportion of non-quota species in the catch. In contrast, catch in the North Sea is dominated (i.e. in excess of 90 per cent) by quota species. The Nephrops trawlers are predominantly based in Scotland, and operate in the North Sea as well as off the west coast of Scotland. 
Nephrops are also caught in the Irish Sea, a high proportion of which is caught by vessels moving down from the west coast of Scotland on a seasonal basis.

The focus of this study is the whitefish trawlers as these have been most adversely affected by quota cuts. In contrast, Nephrop fisheries have experienced increased stock sizes over recent years, largely as a result of the reduction in predation from whitefish.

\section{Long run and short run measures of capacity}

The concept of capacity has been well established in the economics literature. Johansen (1968) defines capacity as "the maximum amount that can be produced per unit of time with existing plant and equipment, provided that the availability of variable factors of production is not restricted". This primal measure of capacity does not take into account the additional costs of increasing output, and is essentially an "engineering" or "technological-economic" definition (Felthoven and Morrison Paul, 2004). In contrast, Klein (1960) defined capacity output as the level of output corresponding to the minimum point of a short-run average cost curve, while Berndt and Morrison (1981), Morrison (1985) and Seguerson and Squires (1990) defined capacity output as the level of output corresponding to the tangency between short-run and long-run average cost curves. These definitions relate to essentially short run measures of capacity, as the assumption is that capital remains fixed. Indeed, in most instances, capacity is considered a short term concept. 
Earlier studies, however, considered long run concepts of capacity. Cassel (1937) and Hickman (1964) suggested that capacity corresponded to the level of output at which the long-run total cost curve was at its minimum. This requires changes in the level of fixed inputs as well as variable inputs. Such a definition, however, has been found to have limited practical value, as empirical studies of the average cost function have tended to conclude that the long-run curve is either linear (Klein, 1960) or "L-shaped" (Prior, 2003) rather than the usually assumed "U-shaped", and hence defining a minimum is not feasible.

The difficulty in estimating long run cost curves is primarily a function of the available data. Most cost functions are estimated using either cross sectional or panel data. However, in any one time period, the data are short run by nature, with total cost and output being a function not only of the level of capital but also its utilisation. Further, different levels of efficiency exist that distort the relationship between capital and output. As the purpose of this study was to consider the fleet size and configuration that, if fully utilised, could harvest the available catch at the least cost, then it is desirable to remove these effects from the data in order to directly estimate a long run cost function.

To this end, a two stage approaches was adopted. First, the fully utilised level of output (i.e. the capacity output) of each vessel given its level of fixed inputs was estimated using Data Envelopment Analysis (DEA). The information produced using DEA was used to adjust the output as well as the variable costs associated with producing this level of output. Although DEA was initially used to overcome 
these data deficiencies, it also provided useful information on returns to scale and optimal vessel size. A translog cost function was then estimated using the adjusted data in order to determine the long run cost function and the cost-minimising level of production.

\subsection{Data Envelopment Analysis}

DEA is a linear programming (non-parametric) method for estimating a production possibility frontier, and where individual firms lie in relation to the frontier. The method is data driven, and, in the context of the fishery, the frontier is defined based on the actual output of boats in the fishery, thereby conforming to the assumption of normal fishing behaviour. Felthoven and Morrison Paul (2004) describe these approaches as "technological-economic", as the derived relationships are based on observed data that implicitly reflect underlying economic decisions. If all fishers operating on the frontier maximised profit and faced similar cost functions to those operating at lower levels of utilisation, then this would be a reasonable approximation to an economically efficient measure of capacity. The measures are essentially short run in nature, as the assumption is that output is maximised given the existing set of fixed inputs.

Although the estimation of capacity in fisheries using DEA is relatively new, a number of studies have already emerged (e.g. Pascoe et al., 2001; Dupont et al., 2002; Felthoven, 2002; Vestergaard et al., 2003; Tingley et al., 2003; Kirkley et al., 2003; Reid et al. 2003; Walden et al., 2003; Tingley and Pascoe, 2005). 
The traditional DEA model of capacity output given current use of fixed inputs is given as:

\section{$\operatorname{Max} \theta_{1}$}

subject to

$$
\begin{aligned}
& \theta_{1} y_{0, m} \leq \sum_{k} z_{k} y_{k, m} \quad \forall k \\
& \sum_{k} z_{k} x_{k, i} \leq x_{0, i} \quad i \in \alpha \\
& \sum_{k} z_{k}=1 \\
& z_{k} \geq 0
\end{aligned}
$$

where $\theta_{1}$ is a scalar denoting how much the output of the target boat (i.e. $k=0$ ) can be increased, $y_{k, m}$ is the output $m$ produced by boat $\mathrm{k}, x_{k, i}$ is the amount of input $i$ used by boat $k$ and $z_{k}$ are the weights that relate the target boat to the set of peers (i.e. the vessels against which it is compared). The restriction $\sum z_{k}=1$ allows for variable returns to scale (VRS), while excluding this constraint implicitly imposes constant returns to scale (CRS). The sum of the weights when CRS is imposed provides an indication of the returns to scale. $\sum z_{k}<1$ implies the vessel is subject to increasing returns to scale while $\sum z_{k}>1$ implies decreasing returns to scale. The ratio of the $\theta_{1}$ 's with VRS and CRS imposed provides a measure of the scale efficiency (i.e. scale efficiency $=\theta_{V R S} / \theta_{C R S}$ ).

Inputs are divided into fixed factors, defined by the sub-set $\alpha$, and variable factors defined by the sub-set $\hat{\alpha}$. For the purposes of estimating capacity, only 
fixed inputs are considered. The value of $\theta_{1}$ is estimated for each vessel separately (i.e. so effectively a set of $\theta_{1, k}$ are estimated), with the target boat's outputs and inputs being denoted by $y_{0, m}$ and $x_{0, i}$ respectively.

Capacity utilisation $(C U)$ is defined as $\mathrm{CU}=1 / \theta_{1}$. The measure of $\mathrm{CU}$ ranges from zero to 1 , with 1 being full capacity utilisation (i.e. 100 per cent of capacity). The capacity output of each vessel is determined by $y_{k, m}^{\prime}=\theta_{1} y_{k, m}$.

A firm's outputs may not be produced efficiently and hence some of the apparent capacity under-utilisation may actually be due to technical inefficiency (i.e. not producing to the full potential given the level of both fixed and variable inputs). If all inputs (both fixed and variable) are not being used efficiently, then it would be expected that output could increase even without an increase in the level of variable inputs through the more efficient use of these inputs.

By comparing the capacity output to the technically efficient level of output, the effects of inefficiency can be separated from capacity under-utilisation. Further, the ratio of these measures has been found to be less susceptible to bias due to random error than the initial capacity utilisation and efficiency estimates (Holland and Lee, 2002).

The technically efficient level of output requires an estimate of technical efficiency of each firm, and requires both variable and fixed inputs to be considered. The DEA model for this is given by: 
$\operatorname{Max} \theta_{2}$

subject to

$$
\begin{aligned}
& \theta_{2} y_{0, m} \leq \sum_{k} z_{k} y_{k, m} \quad \forall m \\
& \sum_{k} z_{k} x_{k, i} \leq x_{0, i} \quad \forall i \\
& \sum_{k} z_{k}=1 \\
& z_{k} \geq 0
\end{aligned}
$$

where $\theta_{2}$ is a scalar outcome denoting how much the production of each firm can increase by using inputs (both fixed and variable) in a technically efficient configuration. In this case, both variable and fixed inputs are constrained to their current level and $\theta_{2}$ represents the extent to which output can increase through using all inputs efficiently. The technically efficient level of output $\left(y_{T E}^{*}\right)$ is defined as $\theta_{2}$ multiplied by observed output $(y)$. The level of technical efficiency is estimated as:

$$
T E=1 / \theta_{2}
$$

An estimate of capacity utilisation excluding efficiency effects $\left(C U^{*}\right)$ is derived by:

$$
C U^{*}=\frac{C U}{T E}=\frac{1}{\theta_{1}} / \frac{1}{\theta_{2}}=\frac{\theta_{2}}{\theta_{1}}
$$


As $\theta_{1} \geq \theta_{2} \geq 1, C U \leq C U^{*} \leq 1$. The difference between the measures reflects the degree to which random variation and technical inefficiency affect the output levels of the different firms.

\subsection{Cost function approach}

An implicit assumption of a primal approach such as implicit in the DEA model illustrated above is that output can increase to the full utilisation level. Under an ITQ system, economic efficiency is determined by cost minimisation given the quota allocation rather than output maximisation given the set of inputs available to the fisher. While the DEA model can be specified with an input orientation, and hence can provide a measure as to the extent to which input use can be reduced to achieve efficient production, this does not provide information on the capacity of the vessel. With ITQs, vessels can adjust output levels, but have incentives to produce this output at the lowest cost possible. For this reason, the estimation of the cost function can be considered a more appropriate means of assessing capacity under an ITQ system. Relatively few applications of the cost function approach have been made in fisheries (see Lipton and Strand 1992, Weninger 1998, Bjørndal and Gordon 2000), largely due to difficulties in obtaining cost and revenue data for commercial fishing vessels.

The translog cost function for a single output industry ${ }^{4}$ can be specified as 


$$
\begin{aligned}
\operatorname{LnC}= & \beta_{o}+\sum_{i}^{n} \alpha_{i} \ln w_{i}+\frac{1}{2} \sum_{i}^{n} \sum_{j}^{n} \alpha_{i j} \ln w_{i} \ln w_{j}+\beta_{y} \ln y+\frac{1}{2} \beta_{y y}(\ln y)^{2}+ \\
& \sum_{i}^{n} \beta_{i y} \ln w_{i} \ln y+\varepsilon
\end{aligned}
$$

where $C$ is the total cost, $w_{i}$ is the price of input $i$ and $y$ is the (aggregated) level of output. By differentiating equation 5 with respect to the input prices and using Shephard's lemma, the set of cost-minimising factor cost shares can be derived, given by

$$
S_{i}=\alpha_{i} \ln w_{i}+\sum_{j}^{n} \alpha_{i j} \ln w_{j}+\beta_{i q} \ln Q+\varepsilon
$$

where $S_{i}$ is the cost share of the $i$ th input, given by wi $x_{i} / C$.

The cost function and the associated set of share equations need to be estimated simultaneously. As the input shares sum to 1 (one), one of the share equations needs to be excluded in order to avoid problems of singularity. A number of restrictions also need to be imposed on the system to ensure consistency with economic theory. Homogeneity in input prices and output requires $\sum_{i}^{n} \alpha_{i}=1, \sum_{i}^{n} \alpha_{i j}=0$, and $\sum_{i}^{n} \beta_{i y}=0$, while symmetry in input prices requires $\alpha_{i j}=\alpha_{j i}$. 
The set of coefficients from estimating the system provides additional information about the nature of the production system, including the propensity to respond to input price changes by changing input use or even substitute inputs, and the returns to scale associated with different production levels. The Allen partial elasticities of substitution between the factor inputs $\left(\sigma_{i j}\right)$ are given by

$$
\sigma_{i i}=\left(\alpha_{i i}+S_{i}^{2}-S_{i}\right) / S_{i}^{2}, \sigma_{i j}=\left(\alpha_{i j}+S_{i} S_{j}\right) / S_{i} S_{j}
$$

and the partial price elasticity of demand for input factor $i\left(\eta_{i}\right)$ are given by

$$
\eta_{i}=\sigma_{i i} S_{i}, \eta_{i j}=\sigma_{i j} S_{j}
$$

A positive elasticity of substitution and cross price elasticity indicates substitution possibilities exist, while negative values indicate a complementary relationship.

The returns to scale of an individual vessel can be given by

$$
R T S=1 /(\partial C / \partial R)=1 /\left(\beta_{y}+\beta_{y y} \ln Y+\sum_{i} \beta_{i y} \ln w_{i}\right)
$$

The inclusion of both fixed and variable costs in the cost function implicitly assumes that the vessels are operating at their long run optimum level. However, where capital has a relatively long life, such as in the case of fishing vessels, capacity may not be fully utilised. In such a case, the fisher may be operating on 
the short term cost curve rather that the long term cost curve. Al-Mutairi and Burney (2002) suggest that in such cases it is more appropriate to estimate the short term cost curve (i.e. excluding fixed and capital costs) and include a variable representing the level of capacity utilisation. Further, inefficiency may exist in the industry that could result in bias in the estimated coefficients if ignored (see Kumbhaker 2001). As adjustment in the fishery as a result of ITQs is likely to result in a more efficient fleet on average, assuming current efficiency levels may not be appropriate.

Given this, three separate cost functions were estimated. The first is the standard cost function presented in equations 5 and 6 . Second, the output measure was adjusted using the results of the DEA analysis to reflect the full capacity output. Costs and cost shares were similarly adjusted to represent the full capacity output. Finally, output and costs were adjusted to represent the fully efficient, full capacity level of output. This latter model is assumed to be consistent with a long run cost function for a fishery not subject to excess capacity.

\section{Data}

Data on costs, revenues and physical characteristics for 67 UK demersal whitefish trawlers relating to the 2001 financial year were available, representing roughly 9 per cent of the total whitefish trawl fleet. These vessels were all above $10 \mathrm{~m}$ in length. ${ }^{5}$ A summary of the key characteristics of the data set is presented in Table 1. 
Although the data are relatively old, more recent data are subject to problems that limit their usefulness for such an analysis. Although the main stocks exploited by the fleet segments under consideration have been declining since the early 1980s, catch restrictions have generally not declined by the same degree. As a result, quotas were not fully binding in many years. Total Allowable Catch (TAC) reductions in excess of 50 per cent were imposed for many North Sea stocks in 2002, whilst most other stocks were subject to TAC reductions of between 10 and 30 per cent (DG Fish, 2001). Further cuts in quotas of the order of between 30 and 50 per cent were made in both 2003 and 2004. By 2005, the UK cod quota was less than 28 per cent of its level in 1999 , and only 18 per cent of that a decade ago. These quota cuts have had a substantial impact on capacity utilisation and have distorted the recorded output mix (i.e. overquota catch is discarded or, in some cases landed illegally, so that the recorded output is not representative of the actual production of the vessels). As the methods for assessing capacity utilisation are data driven and relative, comparing vessels in more recent years where all are substantially underutilised would result in the derived (relative) average utilisation measure being fairly high. Consequently, the average costs would appear substantially greater than they should if the fleet were fully utilised, even given the low stock levels.

The individual cost items were aggregated into four cost categories: crew costs, running costs, capital costs and 'other' costs. Crew costs were the payments to crew. Running costs consisted of fuel costs, ice, box charges and food. Information on the capital value of the vessel was not provided by most skippers. 
However, where information on capital values was provided, this was generally based on the insurance value of the vessel. The insurance cost was therefore used as a proxy measure for capital costs. All other costs were included in the 'other' cost category.

Data on input prices were not available, but proxy measures of input prices were derived from the survey data. The crew price was derived from total crew payments divided by the number of crew. This is a potentially misleading measure, as crew are paid a share of the net revenue (i.e. revenue less running costs). As a result, a relatively high crew price may indicate a relatively high labour productivity, but may also be a consequence of 'luck' (i.e. higher than expected catches). Running costs are a function of both the amount of time fished and the size of the vessel. Information on fishing effort (e.g. days fished) was not available for most of the vessels. The input price associated with running costs was assumed to be the running cost of the vessel if it was operating at full capacity divided by the number of vessel capacity unit (VCUs). ${ }^{6}$ An assumption was made that running costs were proportional to the level of capacity utilisation. Hence the running cost if fully utilised was given by the observed running cost divided by the capacity utilisation rate. ${ }^{7}$ The prices of capital and other inputs were also derived from the costs information and the physical boat characteristics. Various combinations of measures were tried. The physical measures that resulted in the lowest variance in input prices were length for 'other costs' and the VCUs for capital costs. Input prices for other costs and capital costs were therefore taken as other costs per unit length and insurance cost per VCU. 
As mentioned in the methodology section, the analysis was also run assuming full capacity utilisation and full efficiency. The level of capacity utilisation and technical efficiency were derived using DEA. The revenue and running costs were scaled up by the appropriate factor for each analysis. Crew are currently paid a share of the revenue (and hence capture some of the rent). As a consequence, the price of labour and crew costs were also assumed to increase in proportion to the revenue increase.

The costs and revenue values were normalised (after appropriate adjustments to account for capacity utilisation and efficiency) such that the mean values of the normalised data were 1 .

\section{Empirical results}

\subsection{DEA: Capacity utilisation, efficiency and returns to scale}

The DEA model was run with revenue as the output measure and length and engine power as the fixed inputs. Fuel costs, which were assumed to be proportional to days fished, were included as the variable input for the purposes of estimating technical efficiency and the 'unbiased' estimate of capacity utilisation. Estimates of capacity utilisation were also obtained for the case of both constant returns to scale and variable returns to scale. The ratio of these measures provides a measure of the scale efficiency. 
A summary of the DEA results is presented in Table 2. On average, the vessels were operating at around 87 per cent capacity and at around 69 per cent efficiency. If the vessels operated at both full capacity and efficiency, average output could potentially increase by 67 per cent (i.e. 1/0.6). In contrast, if the vessels were fully utilised but remained at their current (in)efficiency levels, potential output could increase by around 15 per cent on average.

Scale efficiency was estimated relative to both capacity utilisation and technical efficiency. The seiners and North Sea otter trawlers were, on average, closer to the 'optimal' scale. The optimal scale in this case is defined where constant returns to scale exist. Both these boat groups were larger, on average, than the other two in terms of length and engine power as well as in terms of output.

A measure of returns to scale can be derived from the sum of the weights from the CRS technical efficiency model. Only four boats were found to be operating at the optimal scale, with three boats operating at above the optimal scale (and therefore subject to decreasing returns to scale). The remaining vessels were all found to be operating with increasing returns to scale. Of the four boats operating at the optimal scale, only 2 were both fully efficient and operating at full capacity. These vessels where $26 \mathrm{~m}$ and $30 \mathrm{~m}$ in length with respective engine powers of $750 \mathrm{~kW}$ and $500 \mathrm{~kW}$, and respective revenues of $£ 1.16$ and $£ 0.97 \mathrm{~m}$ (an average revenue of $£ 1.06 \mathrm{~m}$ ). While they were at the top end of the vessels in the fleet (in terms of size), they were not the largest vessels. 


\subsection{Cost function}

The cost function was estimated excluding the capital share equation in order to avoid singularity. As mentioned above, three variants of the model were run using different manipulations of the data. The first run was assuming the industry was in a long run equilibrium. The second run took into account capacity underutilisation and the revenue, crew and running costs were re-estimated. The third run took into account the existence of inefficiency as well as capacity underutilisation. In this run, revenues and crew costs were increased to take into account both of these factors while running costs were increased to take into account the increased utilisation only.

The parameter estimates from the three model runs are presented in Table 3. In all three models, most parameters were significant at the 1 per cent level. The adjusted $\mathrm{R}^{2}$ values were also reasonably high for the cost function itself, but less so for the share equations. While the adjusted $\mathrm{R}^{2}$ values varied for the different models, these cannot be compared as the values of the dependent variable also differed in each model run.

The estimated partial own and cross price elasticity for the demand for factor $i$ are presented in Table 4. As would be expected, the own price elasticity was negative for each input and the cross price elasticities were generally positive indicating the potential for substitution. The exception to this was capital and running costs, which were found to have a complementarity relationship. As running costs are a 
function of both the level of capital and its utilisation, an increase in capital prices would lead to lower levels of capital and, consequently, also lower running costs.

The returns to scale derived at the mean prices and output levels for each model is given in Table 5. In all three models, increasing returns were found at the mean. The optimal scale of fishing vessel can be found by solving equation (9) for the case where returns to scale are equal to 1 (one). In the base model, the optimal vessel is 17,020 times greater than the current average sized vessel, suggesting an optimal vessel length or around $254 \mathrm{~km}$ - approximately half the southern UK coastline. Despite this magnitude, the scale factor is not significantly different to zero. In contrast, if considering fully efficient and fully utilised vessels, the optimal scale is about 2.8 times the current average sized vessel, with the value being statistically significant.

\subsection{Optimal vessel size and profits}

From the DEA analysis, the average of the 'optimum' level of output was $£ 1.04 \mathrm{~m}$. The vessels from which this average was obtained were both fully efficient and operating at full capacity. From the cost function analysis, the optimal vessel size (if fully efficient and fully utilised) was 2.793 times larger than the current average vessel. Given that the current average vessel if full efficient and fully utilised would produce revenue of $£ 0.625 \mathrm{~m}$, the optimal vessel size would produce an output of around $£ 1.74 \mathrm{~m}$. 
Although the cost function estimate of optimal yield is 67 per cent greater than the DEA estimate, the lower DEA estimate of optimal output is within the 95 per cent confidence interval of the corresponding cost function estimate. Hence, the two estimates are not statistically significantly different. The DEA estimate of optimal production, by the nature of its calculation, is restricted to be within the range of the available data. Also, the DEA estimate is based on a primal output oriented function with output maximisation the implicit objective. In contrast, the cost function derived estimate of optimal production is not restricted to fall within the range of observed output levels, and the dual function has the objective of minimising costs as well as maximising output in order to maximise profits. However, extending beyond the range of the data creates problems for obtaining reliable and robust estimates. The translog function underlying the cost function is lest robust the further the variable values deviate from 1 .

These difficulties in obtaining reliable estimates not withstanding, estimates of the profits associated with the "optimal" scale vessels are presented in Table 6. These are not true rents, as the non-cash capital costs (i.e. economic depreciation and opportunity cost of capital) have not been taken into account in the estimation of total costs. However, they provide an indication as to the potential increase in vessel profits that may occur through restructuring.

From Table 6, if the vessels tend over time to move to the optimal scale identified by the DEA, then the fleet would need to reduce by nearly two thirds in order to enable the vessels to operate at full capacity (assuming also full efficiency). In 
contrast, if the vessels tend to increase in size over time to the optimal scale identified by the cost function, the fleet size would need to reduce by almost 80 per cent.

\section{Discussion and conclusions}

The estimates of potential profits are based on current stock conditions, which are currently at a low level. If stocks recover, the unit cost of capture will decrease and the potential profit from a fully utilised vessel is likely to increase above that suggested in the above analysis. Further, assuming that the full capacity estimates of output are, in fact, representing the capacity of the vessel, higher stock levels would be able to support a larger number of vessels than the above analysis suggests.

Both the DEA and cost function approach provide useful information on the level of excess capacity in fisheries. The DEA approach is primarily a short run analysis as it assumes that fixed factors remain fixed and output is a function of their utilisation. From the DEA results, average capacity utilisation was 0.87 , but average technical efficiency was 0.69 . This suggests that inefficiency is a greater problem for the fleet than underutilisation. If all vessels were fully utilised and fully efficiency, then total output would be roughly two thirds greater than the current level. Given that output is currently restricted by quotas, this suggests that excess capacity is excessive in the whitefish fishery. 
The cost function approach provides a longer-term perspective in that it allows for all inputs to vary. Further, when output is restricted such as through ITQs, then incentives exist to minimise costs rather than maximise output. Hence, the cost function approach is theoretically more appropriate than the output oriented DEA approach. However, a difficulty arises if fixed inputs are underutilised in the short term. As seen from the econometric results, ignoring capacity under-utilisation in the estimation of the cost function results in unrealistic 'optimal' levels of output. Combining the results of the DEA capacity utilisation analysis into the cost function analysis overcame this problem.

The cost function approach, however, requires detailed information on factor input prices. This is a particular problem when cross sectional data are used, such as in this study. When a time series of data are available, then industryindependent price indexes can be constructed for factors such as fuel, labour (e.g. average wage) and capital (e.g. interest rate) that vary from year to year. However, within a given time period, all firms face the same set of prices, so an industryindependent set of price indexes are not appropriate. Deriving proxy measures for input prices from the available data may result in measurement error that could affect the regression results. Further, apparent differences in 'prices' may reflect heterogeneity in input quality. For example, in the fleet segments examined, crew costs are based on a share of the revenue less running costs. While average crew earnings can be derived as a proxy for the price of labour, price differentials most likely reflect differences in skill of the crew and skipper. Labour in such a case is 
not a homogeneous input. Adjusting the crew costs and labour price for differences in efficiency overcomes this problem to an extent.

Capturing the full capital cost and appropriate cost of capital in an ITQ fishery is also problematic. While interest rates can be considered an appropriate price of capital, this is common to all vessels within a given time period. The approach adopted in this study was to use the average insurance cost per unit of physical capital. Again, this is subject to measurement errors as it assumes that the insurance costs are proportional to the value of capital invested.

These problems not withstanding, the results from the cost function conformed with a priori expectations with respect to the signs of the derived own and cross price elasticities of demand. Further, the derived scale elasticities were consistent with the returns to scale estimated using DEA, and the 'optimal' scale estimated using both DEA and the cost function were not significantly different.

The results of the study suggest that the whitefish demersal fleet is likely to adjust in both scale and size to consist of fewer, but larger vessels than currently exist. This consolidation of fishing activity into fewer, larger units has been commonly observed in other fisheries subject to ITQ management, and is often used as an argument by industry to prevent their implementation. In the UK, transferability is limited and involves high transactions costs. While this may slow the rate of adjustment, pressures exist for managers to reduce capacity in line with the reduction in the resource base. As a consequence, fleet sizes will, by necessity, 
decrease, and the social problems associated with fleet reduction (e.g. increased unemployment in rural areas), will have to be incurred. Freeing up quota transferability may facilitate this process at lower cost to the taxpayer and result in greater long run economic benefits (in terms of rent generation) than other capacity reduction management measures.

\section{Acknowledgements}

This project was undertaken as part of the EU funded project "Modelling fishermen behaviour under new regulatory regimes" (QLRT-2000-01535).

\section{References}

Alam, M.F., Omar, I.H, and Squires, D. (2002) Sustainable fisheries development in the tropics: trawlers and licence limitation in Malaysia, Applied Economics, 34, 325-337.

Al-Mutairi, N. and Burney, N.A. (2002) Factor substitution, and economies of scale and utilisation in Kuwait's crude oil industry, Energy Economics, 24, $337-354$.

Berndt, E.R. and Morrison, C.J. (1981) Capacity utilisation measures: underlying economic economic theory and alternative approaches, American Economic Review, 71(2), 48-52.

Bjørndal, T. and Gordon, D.V. (2000) The Economic Structure of Harvesting for Three Vessel Types in the Norwegian Spring-Spawning Herring Fishery, Marine Resource Economics, 15, 281-292. 
Cassels J.M. (1937) Excess capacity and monopolistic competition, Quarterly Journal of Economics, 51, 426-443.

DEFRA (2003) UK Sea Fisheries Statistics 2002 (and earlier issues). DEFRA.

Del Valle, I., Astorkiza, I. and Astorkiza K. (2003) Fishing effort validation and substitution possibilities among components: the case study of the VIII division European anchovy fishery, Applied Economics, 35, 63-77.

DG Fish (2000) MAGP IV not effective enough in dealing with overcapacity. EU press release $01.10 .2000, \quad$ [available online from http://www.europa.eu.int/comm/fisheries/pcp/faq2_en.htm]

DG Fish. (2001) Fisheries: "alarming state of fish stocks" requires further substantial cuts for 2002 fishing catches, EU press release 4.12.2001. [available online from http://www.europa.eu.int/comm/fisheries/newscorner/press/info01_70_en.htm ]

Dupont, D.P., Grafton, R.Q., Kirkley, J. and Squires D. (2002) Capacity utilization measures and excess capacity in multi-product privatized fisheries, Resource and Energy Economics, 24(3), 193-210.

Felthoven, R.G. (2002) Effects of the American Fisheries Act on capacity, utilisation and technical efficiency, Marine Resource Economics, 17, 181206.

Felthoven, R.G. and Morrison Paul, C.J. (2004) Multi-output, non-frontier primal measures of capacity and capacity utilization, American Journal of Agricultural Economics, 86(3), 619-633. 
Hannesson, R. (1991) From common fish to rights based fishing: Fisheries management and the evolution of exclusive rights to fish, European Economic Review, 35(2-3), 397-407.

Hickman, B.G. (1964) On a new method for capacity estimation, Journal of the American Statistical Association, 59, 529-549.

Holland D.S. and Lee S.T. (2002) Impacts of random noise and specification on estimates of capacity derived from Data Envelopment Analysis, European Journal of Operational Research, 137(1), 10-21.

ICES. (2003) Report of the ICES Advisory Committee on Fishery Management, 2003, [Available from www.ICES.dk]

Johansen, L. (1968) Production functions and the concept of capacity. Recherches recentes sur la fonction de production, Centre d'Etudes et de le Recherche Universitaire de Namur.

Kirkley, J.E., Squires, D. and Strand, I.E. (1985) Assessing technical efficiency in commercial fisheries: The Mid-Atlantic Sea Scallop Fishery, American Journal of Agricultural Economics, 77(3), 686-97.

Kirkley, J.E., Squires, D., Alam, M.F. and Ishak, H.O. (2003) Excess capacity and asymmetric information in developing country fisheries: the Malaysian purse seine fishery, American Journal of Agricultural Economics, 85(3), $647-662$.

Kirkley, J.E. and Strand, I.E. (1988) The technology and management of multispecies fisheries, Applied Economics, 20, 1279-1292.

Klein, L.R. (1960) Some theoretical issues in the measurement of capacity, Econometrica, 28, 272-286. 
Kompas, T., Che, T.N. and Grafton, R.Q. (2004) Technical efficiency effects of input controls: evidence from Australia's banana prawn fishery, Applied Economics, 36, 1631-1641.

Kumbhakar, S.C. (2001) Estimation of profit functions when profit is not maximum, American Journal of Agricultural Economics 83(1), 1-19.

Lipton, D.W. and Strand, I.E. (1992) Effect of Stock Size and Regulations of Fishing Industry Cost and Structure: The Surf Clam Industry, American Journal of Agricultural Economics, 74, 197-28.

Morrison, C.J. (1985) Primal and dual capacity utilisation: an application to productivity measurement in the U.S. automobile industry, Journal of Business and Economic Statistics, 3(4), 312-324.

Pascoe, S., Andersen, J.L. and de Wilde, J. (2001) The Impact of Management Regulation on the Technical Efficiency of Vessels in the Dutch Beam Trawl Fishery, European Review of Agricultural Economics, 28, 187-206.

Pascoe, S., Coglan, L. and Mardle, S. (2001) Physical versus harvest based measures of capacity: the case of the UK vessel capacity unit system. ICES Journal of Marine Science, 58(6), 1243-1252.

Pascoe, S., Tingley, D. and Mardle, S. (eds). (2003) Technical efficiency in EU fisheries: implications for monitoring and management through effort controls: Final Report, CEMARE, University of Portsmouth, UK.

Prime Minister's Strategy Unit (2004) Net Benefits A sustainable and profitable future for UK fishing, Cabinet Office, HMSO, London. 
Prior, D. (2003) Long- and short-run non-parametric cost frontier efficiency: and application to Spanish savings banks, Journal of Banking and Finance, 27, $655-671$.

Reid, C., Squires, D., Jeon, Y., Rodwell, L. and Clarke, R. (2003) An analysis of fishing capacity in the western and central Pacific Ocean tuna fishery and management implications, Marine Policy 27(6), 449-469.

Rural Development Committee (2003) Report on inquiry into current issues facing the Scottish fishing industry, Scottish Parliament Paper 789, Edinburgh.

Segerson, K. and Squires, D. (1990) On the measurement of economic capacity utilization for multi-product industries, Journal of Econometrics, 44, 347361.

Tingley, D., Pascoe, S. and Mardle S. (2003) Estimating capacity utilisation in multi-purpose, multi-metier fisheries. Fisheries Research, 63(1), 121-134.

Tingley, D. and Pascoe S. (2005) Factors affecting capacity utilisation in fisheries, Journal of Agricultural Economics, 56(2), 287-307.

Vestergaard, N., Squires, D. and Kirkley, J.E. (2003) Measuring capacity and capacity utilization in fisheries: the case of the Danish gillnet fleet, Fisheries Research, 60(2-3), 357-368.

Weninger, Q. (1998) Assessing Efficiency Gains from Individual Transferable Quotas: An Application to the Mid-Atlantic Surf Clam and Ocean Quahog Fishery. American Journal of Agricultural Economics 80, 750-764. 
Weninger, Q. and Strand, I. (2003) An empirical analysis of production distortions in the mid-Atlantic surf clam and ocean quahog fishery, Applied Economics, 35, 1191-1197.

Walden J.B., Kirkley J.E., Kitts A.W. (2003) A limited economic assessment of the Northeast groundfish fishery buyout program. Land Economics 79(3), 426-439.

Editorial Office, Dept of Economics, Warwick University, Coventry CV4 7AL, UK 


\section{Footnotes}

${ }^{1}$ A fishery is generally considered to consist of a set of vessels targeting a similar set of species in a particular geographical area. Usually, the size of the geographical area is defined by the distribution of the stock. For some species, this can be expansive, while for other species it may be a relatively small area. As several different types of fishing gear are often used, the fishery is broken down into a number of fleet segments.

${ }^{2}$ Production functions and stochastic production frontiers have been employed to consider the implications of input controls in fisheries (e.g. Pascoe et al 2001, Del Valle et al 2003, Weninger and Strand 2003, Kompas et al 2004). The assumption underlying these analyses is that capital is effectively fixed in the short term, and that incentives exist to maximise output or revenue (e.g. Kirkley and Strand, 1988). When considering the adoption of individual transferable quotas, this assumption is not valid, as fishers would be expected to adjust their capital in order to minimise the costs given the output constraint. Hence, a cost or profit function may be considered more appropriate (see Lipton and Strand 1992 and Alam et al 2002 for examples).

3 The delineation of the fleet into "over $10 \mathrm{~m}$ " and " $10 \mathrm{~m}$ and under" length categories has implications for management regulations both within the UK and also at the European level. The under $10 \mathrm{~m}$ fleet segment dominate the industry in terms of vessel numbers (74 per cent in 2002 (DEFRA 2003)), but contribute less than 10 per cent of the value of the catch. The under $10 \mathrm{~m}$ fleet are not subject to individual quota controls, but are generally subject to catch limits that vary month to month. 
${ }^{4}$ The cost function can also be developed for a multi-output industry. The single output case is presented for the sake of simplification.

${ }^{5}$ Data on a small number of vessels under $10 \mathrm{~m}$ were also available. As these vessels are not subject to the same individual quota regulations as the larger vessels these data were not used. The data were collected through personal interview by the Seafish Industry Authority for the North Sea and Irish Sea, and by CEMARE for the English Channel.

${ }^{6}$ In the UK, VCUs are defined by length*breadth $+0.45^{*}$ engine power. These were found to be highly correlated with fishing capacity in trawl fisheries (see Pascoe, Coglan and Mardle 2001).

${ }^{7}$ This essentially assumes constant returns to fishing effort. Previous studies of revenue functions for the North Sea and English Channel demersal whitefish trawl fleet have found the production elasticity associated with days fished is around 1 (one) (see Pascoe, Tingley and Mardle 2003), suggesting that such an assumption is realistic. 
Table 1. Key characteristics of the sample, 2001

\begin{tabular}{lrrrrrr}
\hline Fleet segment & $\begin{array}{r}\text { No of } \\
\text { obs. }\end{array}$ & $\begin{array}{r}\text { Average } \\
\text { length }\end{array}$ & $\begin{array}{r}\text { Average } \\
\text { engine power }\end{array}$ & $\begin{array}{r}\text { Average } \\
\text { crew }\end{array}$ & $\begin{array}{r}\text { Average } \\
\text { revenue }\end{array}$ & $\begin{array}{r}\text { Average } \\
\text { total costs }\end{array}$ \\
& & $(\mathrm{m})$ & $(\mathrm{kW})$ & number & $(\mathfrak{l})$ & $(\mathfrak{l})$ \\
\hline Irish Sea trawlers & 4 & 20.0 & 242 & 2.0 & 140005 & 90596 \\
North Sea trawlers & 42 & 23.6 & 439 & 5.4 & 436255 & 271849 \\
English Channel trawlers & 8 & 14.0 & 224 & 2.0 & 115504 & 61207 \\
Seiners (NS and EC) & 13 & 25.4 & 411 & 5.0 & 399941 & 257121 \\
Total & 67 & 22.6 & 396 & 4.7 & 373224 & 311015 \\
\hline
\end{tabular}


Table 2. Average capacity utilisation and technical efficiency

\begin{tabular}{|c|c|c|c|c|c|}
\hline & \multicolumn{3}{|c|}{ Otter Trawlers } & \multirow[t]{2}{*}{ Seiners } & \multirow[t]{2}{*}{ All boats } \\
\hline & Irish Sea & North Sea & Channel & & \\
\hline Fully efficient CU $\left(1 / \theta_{1}\right)$ & 0.53 & 0.61 & 0.68 & 0.54 & 0.60 \\
\hline Technical efficiency $\left(1 / \theta_{2}\right)$ & 0.59 & 0.68 & 0.79 & 0.67 & 0.69 \\
\hline Capacity utilisation $\left(\mathrm{CU}^{*}\right)\left(\theta_{2} / \theta_{1}\right)$ & 0.88 & 0.89 & 0.86 & 0.82 & 0.87 \\
\hline Scale efficiency: $\mathrm{CU}\left(\theta_{1, \mathrm{VRS}} / \theta_{1, \mathrm{CRS}}\right)$ & 0.71 & 0.88 & 0.46 & 0.94 & 0.83 \\
\hline Scale efficiency: TE $\left(\theta_{2, \mathrm{VRS}} / \theta_{2, \mathrm{CRS}}\right)$ & 0.83 & 0.92 & 0.70 & 0.96 & 0.90 \\
\hline
\end{tabular}


Table 3. Results from econometric analysis

\begin{tabular}{|c|c|c|c|c|c|c|}
\hline & \multicolumn{2}{|c|}{ Base Run } & \multicolumn{2}{|c|}{ Full capacity utilisation } & \multicolumn{2}{|c|}{ Technically efficient full CU } \\
\hline & Coeff & St. Err. & Coeff & St. Err. & Coeff & St. Err. \\
\hline Constant & -0.023 & 0.020 & -0.018 & 0.028 & -0.029 & 0.030 \\
\hline Crew & 0.343 & $0.009 * * *$ & 0.357 & $0.011 * * *$ & 0.429 & $0.014 * * *$ \\
\hline Running & 0.240 & $0.006 * * *$ & 0.243 & $0.004 * * *$ & 0.196 & $0.005 * * *$ \\
\hline Other & 0.349 & $0.006 * * *$ & 0.327 & $0.006 * * *$ & 0.278 & $0.005 * * *$ \\
\hline Capital & 0.068 & $0.006 * * *$ & 0.073 & $0.006 * * *$ & 0.097 & $0.014 * * *$ \\
\hline Revenue & 0.549 & $0.030 * * *$ & 0.630 & $0.050 * * *$ & 0.754 & $0.064 * * *$ \\
\hline $\mathrm{Crew}^{2}$ & 0.003 & 0.013 & 0.024 & 0.010 ** & 0.051 & $0.009 * * *$ \\
\hline Running $^{2}$ & 0.065 & $0.013 * * *$ & 0.101 & $0.008 * * *$ & 0.096 & $0.008 * * *$ \\
\hline Other $^{2}$ & 0.100 & $0.014 * * *$ & 0.046 & $0.009 * * *$ & 0.039 & $0.011 * * *$ \\
\hline Capital $^{2}$ & 0.017 & $0.010 *$ & 0.016 & $0.009 *$ & -0.003 & 0.019 \\
\hline Revenue $^{2}$ & 0.023 & 0.017 & 0.069 & $0.023 * * *$ & 0.120 & $0.021 * * *$ \\
\hline Crew*running & -0.019 & 0.022 & -0.056 & $0.010 * * *$ & -0.085 & $0.007 * * *$ \\
\hline Crew*other & -0.061 & $0.019 * * *$ & -0.057 & $0.012 * * *$ & -0.082 & $0.007 * * *$ \\
\hline Crew*capital & 0.074 & $0.017 * * *$ & 0.066 & $0.010 * * *$ & 0.065 & $0.018 * * *$ \\
\hline Crew*revenue & 0.014 & 0.016 & 0.019 & 0.017 & 0.031 & 0.020 \\
\hline Running*other & -0.070 & $0.018 * * *$ & -0.042 & $0.012 * * *$ & -0.021 & 0.014 \\
\hline Running*capital & -0.040 & 0.017 ** & -0.104 & $0.013 * * *$ & -0.085 & $0.020 * * *$ \\
\hline Running*revenue & 0.053 & $0.013 * * *$ & -0.002 & 0.010 & 0.001 & 0.011 \\
\hline Other*capital & -0.069 & $0.020 * * *$ & 0.007 & 0.016 & 0.026 & 0.025 \\
\hline Other*revenue & -0.100 & $0.016 * * *$ & -0.041 & $0.013 * * *$ & -0.030 & $0.014^{* *}$ \\
\hline Capital*revenue & 0.033 & $0.013^{* *}$ & 0.024 & $0.013 *$ & -0.002 & 0.025 \\
\hline Irish & -0.008 & 0.062 & -0.001 & 0.093 & -0.092 & 0.087 \\
\hline Channel & -0.206 & $0.053 * * *$ & -0.162 & $0.080 * *$ & -0.079 & 0.077 \\
\hline Seine & 0.042 & 0.034 & 0.001 & 0.050 & -0.016 & 0.049 \\
\hline \multicolumn{7}{|l|}{ Adjusted $R^{2}$} \\
\hline Total costs & & 0.969 & & 0.934 & & 0.901 \\
\hline Running share & & 0.573 & & 0.723 & & 0.505 \\
\hline Other share & & 0.380 & & 0.562 & & 0.561 \\
\hline Crew share & & 0.150 & & 0.245 & & 0.189 \\
\hline
\end{tabular}

*** significant at $1 \%$ level; ** significant at $5 \%$ level; * significant at $10 \%$ level 
Table 4. Own and cross price elasticities for demand for the factor inputs

\begin{tabular}{|c|c|c|c|c|c|c|c|c|}
\hline \multirow[b]{2}{*}{ Base run } & \multicolumn{2}{|l|}{ Crew } & \multicolumn{2}{|l|}{ Running } & \multicolumn{2}{|l|}{ Other } & \multicolumn{2}{|l|}{ Capital } \\
\hline & & & & & & & & \\
\hline Crew & -0.650 & $* * *$ & 0.177 & $* * *$ & 0.177 & $* * *$ & 0.288 & $* * *$ \\
\hline Running & 0.260 & $* * *$ & -0.489 & $* * *$ & 0.054 & & -0.104 & \\
\hline Other & 0.170 & $* * *$ & 0.035 & & -0.364 & $* * *$ & -0.123 & $* *$ \\
\hline Capital & 1.401 & $* * *$ & -0.343 & & -0.621 & $* *$ & -0.683 & $* * *$ \\
\hline \multicolumn{9}{|l|}{ Full CU } \\
\hline Crew & -0.569 & $* * *$ & 0.094 & $* * *$ & 0.168 & $* * *$ & 0.243 & $* * *$ \\
\hline Running & 0.139 & $* * *$ & -0.344 & $* * *$ & 0.156 & $* * *$ & -0.359 & $* * *$ \\
\hline Other & 0.190 & $* * *$ & 0.119 & $* * *$ & -0.535 & $* * *$ & 0.084 & $*$ \\
\hline Capital & 1.414 & $* * *$ & -1.410 & $* * *$ & 0.434 & $*$ & -0.678 & $* * *$ \\
\hline \multicolumn{9}{|c|}{ Full TE CU } \\
\hline Crew & -0.425 & $* * *$ & 0.024 & & 0.098 & $* * *$ & 0.192 & $* * *$ \\
\hline Running & 0.055 & & -0.330 & $* * *$ & 0.171 & $* *$ & -0.359 & $* * *$ \\
\hline Other & 0.166 & $* * *$ & 0.128 & $* *$ & -0.583 & $* * *$ & 0.146 & \\
\hline Capital & 1.687 & $* * *$ & -1.400 & $* * *$ & 0.761 & & -0.997 & $* * *$ \\
\hline
\end{tabular}


Table 5. Estimated returns to scale

\begin{tabular}{|c|c|c|c|c|c|c|}
\hline & \multicolumn{2}{|c|}{ Base Run } & \multicolumn{2}{|c|}{ Full capacity utilisation } & \multicolumn{2}{|c|}{ Technically efficient full CU } \\
\hline & Coeff & St. Err. & Coeff & St. Err. & Coeff & St. Err. \\
\hline Returns to scale & 1.822 & $0.099 * * *$ & 1.588 & $0.126 * * *$ & 1.327 & $0.111 * * *$ \\
\hline Scale factor & 17020 & 125869 & 14.599 & 16.321 & 2.793 & $1.178^{* *}$ \\
\hline
\end{tabular}


Table 6. Estimated revenues, costs and profits

\begin{tabular}{lccr}
\hline & $\begin{array}{r}\text { Current "average" } \\
\text { vessel }\end{array}$ & $\begin{array}{r}\text { DEA “optimal” } \\
\text { vessel }\end{array}$ & $\begin{array}{r}\text { Cost function } \\
\text { "optimal” vessel }\end{array}$ \\
\hline Revenue (£m) & 0.373 & 1.065 & 1.747 \\
Costs (£m) & 0.311 & 0.633 & 1.182 \\
Profits (£m) & 0.062 & 0.431 & 0.565 \\
Profits as proportion of revenue (\%) & 16.6 & 40.5 & 32.4 \\
Potential fleet reduction (\%) & - & 65 & 79 \\
\hline
\end{tabular}

